Review

\title{
The Role of Lymphostatin/EHEC Factor for Adherence-1 in the Pathogenesis of Gram Negative Infection
}

\author{
Jan-Michael A. Klapproth \\ Division of Digestive Diseases, Emory University, Atlanta GA 30322, USA; \\ E-Mail: jklappr@emory.edu; Tel.: +1-404-727-5638
}

Received: 21 March 2010; in revised form: 22 April 2010 / Accepted: 27 April 2010 /

Published: 5 May 2010

\begin{abstract}
Lymphostatin/EHEC factor for adherence-1 is a novel large toxin represented in various Gram negative bacteria, highly associated with the development of infectious diarrhea and hemolytic uremic syndrome. In vitro and in vivo experiments identified lymphostatin/EFA-1 as a toxin with a central role in the pathogenesis of Gram negative bacteria, responsible for bacterial adhesion, intestinal colonization, immunosuppression, and disruption of gut epithelial barrier function.
\end{abstract}

Keywords: lymphocyte inhibitory factor A/EHEC factor for adherence-1; lymphostatin; Gram negative bacterial toxin; Enteropathogenic E. coli; Enterohemorrhagic E. coli; immunosuppression; Citrobacter rodentium; intestinal epithelial barrier function

\section{Introduction}

Gastrointestinal infections and diarrhea are a worldwide problem with more than 1 billion cases and approximately 2 million deaths annually [1]; 80\% of which children aged 6 months to 3 years. Infectious diarrhea caused by Gram negative bacteria can be due to Enteropathogenic E. coli (EPEC) in developing countries [2], and Enterohemorrhagic E. coli (EHEC) in developed nations [3], complicated by dehydration, weight loss, and hemolytic-uremic syndrome (HUS) [4].

Pathogenic E. coli harbor a large arsenal of pathogenicity genes, located on plasmids and the bacterial chromosome, and effector proteins. An example is the EAF-plasmid (EPEC adherence factor) [5] encoding for a battery of adhesion factors. An additional example is the "locus of 
enterocytes effacement" (LEE) [6] pathogenicity island located on the bacterial chromosome, encoding for more than 40 proteins necessary for the type III secretion system and effector proteins that modify and neutralize host cellular functions. However, not all genes encoding for effector proteins and associated factors implicated in Gram negative pathogenesis are located on the LEE island, and one such example is lifA/e-1 (lymphocyte inhibitory factor A/EHEC factor for adherence-1). Recently, it has become clear that lifA/efa-1 assumes a central role in the pathogenesis of infectious diarrhea.

\section{Molecular Studies}

Pathogenic E. coli, like EPEC and EHEC, cause diarrheal diseases in all age groups. EPEC strains predominantly colonize the small intestine and rely on the virulence plasmid-encoded bundle-forming pili for the formation of microcolonies (localized adherence) and LEE-encoded intimin for intimate attachment to epithelial cells and effacement of micovilli [7]. In contrast, EHEC preferentially colonizes the distal ileum and colon with tropism for follicle-associated epithelium [8]. Like EPEC, EHEC harbors the LEE pathogenicity island, but also possesses phage-encoded Shiga toxins 1 and 2 that induce an intense inflammatory response [9].

lifA/efa-1 is found in pathogenic, but not non-pathogenic, E. coli strains, and is detected exclusively in strains that are capable of attaching and effacing activity, a phenotype encoded by the LEE [10,11]. This gene is present in $87.5 \%$ in EPEC, including atypical EPEC that do not bear the bfp-plasmid [10,12,13], 89.7\%-100\% of EHEC, in particular serotypes O5, O26, O23, and O111 [11,14-17], rabbit Enteropathogenic E. coli (REPEC) serotypes 89/39 and 84/110-1 [18-20], 100\% of Hafnia alvei, and mouse pathogen Citrobacter rodentium. lifA/efa-1 is located on the bacterial chromosome in EPEC, REPEC, and C. rodentium [21]. A similar, large gene with 3,169 codons encoding for a putative $362 \mathrm{kDa}$ product was identified on the large $93 \mathrm{~kb}$ to $104 \mathrm{~kb}$ pO157 virulence plasmid in EHEC strain O157:H7, termed toxB/L7095 [22]. Over its entire length, nucleotide and residue similarity of toxB in comparison to lifA/efa- 1 was only $28 \%$ and $47 \%$, respectively. However, like lifA/efa-1 and large Clostridial cytotoxins, the $\mathrm{N}$-terminus contained sequences encoding for a glucosyltransferase. A truncated lifA/efa-1 pseudogene (efa-1') is located in the O island 122 at $z 4332$ and $z 4333$ on bacterial chromosome of serotype O157:H7 [23].

Interestingly, lifA/efa-1 is also present in various Chlamydia spp strains. C. muridarium harbors three, $C$. psittaci a single lifA/efa-1 gene, $C$. trachomaits a shortened pseudogene, whereas it is not represented in $C$. pneumonia [24]. Therefore, it is conceivable that this toxin is responsible for organ specificity of different Chlamyida spp strains [25].

The association of lifAlefa- 1 with the pathogenesis of infectious diarrhea was established through molecular studies of stool samples [26]. In contrast to typical EPEC strains, atypical EPEC lack the $69 \mathrm{~kb}$ pathogenicity EAF-plasmid and express less bacterial effector proteins. DNA microarray analysis of 182 virulence genes identified lifA/efa- 1 as the gene with the strongest statistical association with infectious diarrhea caused by atypical EPEC strains among Norwegian children, recently confirmed in a patient population from Brazil presenting with acute diarrhea [27]. 
Several groups have shown that lifA/efa-1 in EHEC and atypical EPEC strains can be part of larger novel gene cluster $\left(\mathrm{O} 122, \mathrm{I}_{\mathrm{RW} 1374}\right.$, OI-122) [28], responsible for increased pathogenicity. The $29 \mathrm{~kb}$ pathogenicity complex OI-122 consists of 26 genes, is divided into three modules, and is represented in EHEC O157:H- with a variable repertoire in non-O157:H7 serotypes. Putative virulence genes are found in module 1, constituting genes Z4318, pagC, and Z4322. Module 2 is composed of Z4323, ent, $n l e B$, and $n l e B$, whereas the third module is made up by lifAlefa- 1 alone [29]. Each of these modules is significantly associated with the development of HUS in EHEC O157:H-, but only module 3 is involved in non-O157 Shiga toxin-producing E. coli (STEC). Especially pagC, Z4322, ent, nleE, nleB, and lifA/efa-1 appear to be more prevalent in HUS caused by non-O157 STEC [29,30]. Further, preliminary phenotypic characterization identified ent, nleB, and lifA/efa-1 to be important for bacterial colonization, and pagC, ent, nleB, and lifA/efa- 1 as factors responsible for increased virulence. Genes implicated in survival of infected mice include ent and $n l e B$, with nleB possibly modulating the infectious dose of non-O157 STEC to humans, thereby contributing to the low infectious dose of this Gram negative pathogen. Given the association of nleB and lifA/efa- 1 with the development of HUS, testing for the presence of both genes has been proposed for clinical identification in addition to other methods. From these studies it has become clear that lymphostatin/EFA-1 does not act alone. Interestingly, even cases of HUS caused by atypical EPEC are strictly dependent on the presence of lifA/efa-1 [14].

Besides lifA/efa-1, nleB has also been characterized further regarding its biological activity. It was shown that $n l e B$ augments the inhibitory activity of nleE on $\mathrm{Nf}-\mathrm{kB}$ through $\mathrm{IkB}$ stabilization, preventing its degradation [31]. In particular, nleE is required for maximal inhibition of TNF- $\alpha$ induced IL-8 expression in vitro, pointing to a possible immunosuppressive function of these two bacterial effector proteins.

lifA/efa- 1 encodes for a toxin with a calculated size of approximately $360 \mathrm{kDa}$ (Figure 1), one of the largest known proteins in Gram negative bacteria [10]. Sequencing analysis identified three critical motifs also present in other pathogenic bacteria: glucosyltransferase-, protease-, and aminotransferase motif. The glucosyltransferase motif consists of two critical aspartic acid residues separated by a single codon (Figure 1; DXD), and its activity is essential in the pathogenesis of large Clostridial cytotoxins, inhibiting small GTPases like Ras, Rac, Rho, and Cdc42 through glycosylation [32]. The N-terminal putative products of lifA/efa- 1 exhibits $38 \%$ amino acid similarity to Clostridium difficile toxin A and $\mathrm{B}$ [16]. The second activity associated with the pathogenesis of Gram negative bacteria is the protease motif, catalyzing proteolytic cleavage of the C-terminal fatty acid modification of Rho [33]. The three critical residues for the protease activity are a cysteine, histidine, and aspartic acid (Figure 1; C,H,D). No role in the pathogenicity of Gram negative bacteria has been identified for the aminotransferase motif, consisting of ten residues (Figure 1, TMGKALSASA).

\section{Functions of Lymphostatin/EFA-1}

Initially, lymphostatin/EFA-1 was characterized as an immunosuppressive bacterial effector protein. In vitro studies with $\mathrm{T}$ lymphocytes isolated from peripheral blood [34], gastrointestinal 
mucosa [35], and spleen [36] have shown that lymphostatin/EFA-1 inhibits mitogen-activated cytokine expression. Pre-incubation of lymphocyte cultures with lysates from EPEC, EHEC, and C. rodentium and subsequent $\mathrm{T}$ cell receptor stimulation lead to a dose dependent inhibition of IL-2, IL-4, and IFN- $\gamma$ transcription and protein expression, and proliferation [34,35,37]. This immunosuppressive effect is independent of secondary effects, like apoptosis, IL-10, TGF- $\beta$, or the presence of macrophages [36]. The immunosuppressive function is present in the bacterial supernatant with 20 -fold increased inhibitory activity in comparison to bacterial cell lysates [35].

Figure 1. lifA/efa-1 encodes for lymphostatin/EFA-1, a toxin present in EPEC, EHEC, $C$. rodentium and Chlamydiae strains. lifA/efa- 1 consists of approximately $9.6 \mathrm{~kb}$ with a $\mathrm{C} / \mathrm{G}$ content of $42 \%$ and putative protein molecular weight of $360 \mathrm{kDa}$. DNA sequencing analysis confirmed significant similarity among various Gram negative bacteria. lifA/efa-1 encodes for three enzymatic activities: a glycosyltransferase - (D-X-D, $1.6 \mathrm{~kb}$ ), protease(C, H, D, 4.5, $4.8 \mathrm{~kb}$ ), and aminotransferase motif (TMGKALSASA, $5.8 \mathrm{~kb}$ ).

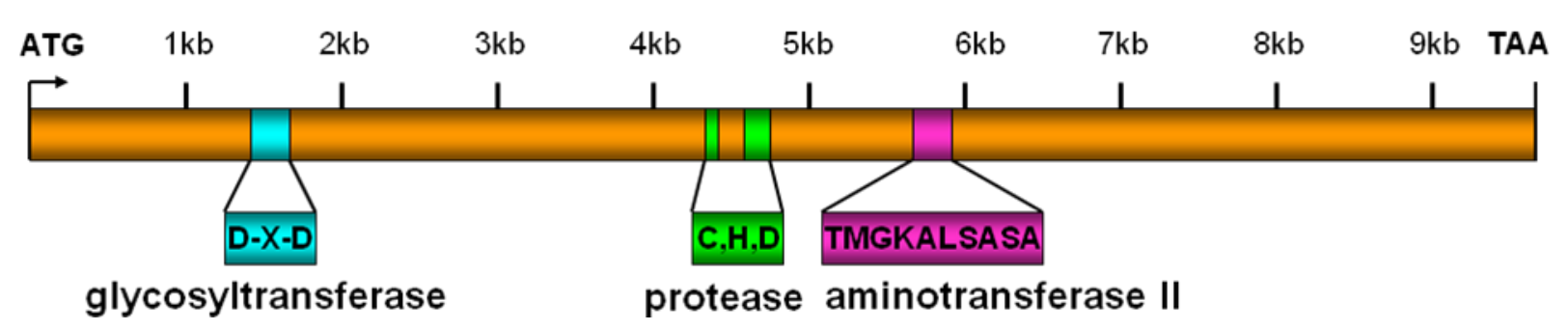

At this time it can only be speculated about the immunosuppressive function of lymphostatin in Chlamydia strains. Chlamydiae are obligatory intracellular pathogenic bacteria that are strictly dependent on tryptophan. Host synthesis of tryptophan is negatively regulated by IFN- $\gamma$. IFN- $\gamma$ induces indolamine-2,3-dioxygenase and converts L-tryptophan into L-formylkynurenin [38]. Therefore, it is conceivable that lymphostatin/EFA-1 from Chlamydia strains suppresses mucosal IFN- $\gamma$ expression, allowing intracellular persistence [24].

As mentioned above, $C$. trachomatis encodes for a lifA/efa-l pseudogene with significant homology to $C$. difficile toxin A and B. Previously, it has been shown that the $\mathrm{N}$-terminal glucosyltransferase activity in C. trachomatis induces cellular ballooning, disassembly of actin fibers, and collapse of cytoskeleton in epithelial cells which is morphologically identical to changes induced by Clostridial toxins A and B [25].

In addition, our group has recently shown that lymphostatin/EFA-1 regulates intestinal epithelial barrier function in vitro and in vivo [39]. Infection of polarized enteric epithelial cells with C. rodentium led to inhibition of small GTPase Cdc42 and activation of RhoA. Inhibition of Cdc42 and activation of RhoA in Caco-2 cells were reversed in cultures incubated with C. rodentium lifAlefa-1 glucosyltransferase and protease motif mutant strains, respectively (Figure 1, above). Inactivation of Cdc42 induced disassembly of adherens junctions, whereas stimulation of RhoA disrupted tight junctions in intestinal epithelial cell cultures. 
Besides an effect on the immune system and intestinal barrier function, lymphostatin/EFA-1 appears to function as an adhesion factor for EHEC and EPEC strains in vitro [16,18], hence the name. In EAF-negative EPEC, deletion of chromosomal lifA/efa-1 and pre-incubation with neutralizing antibodies against lymphostatin/EFA-1 decreased bacterial adhesion to epithelial cells. Similar experiments with EHEC showed that successive inactivation of EHEC lifA/efa-1 on the $93 \mathrm{~kb}$ pathogenicity plasmid and chromosomal pseudogene lead to a 4- and 12-fold reduction in adhesion to epithelial cells in vitro, respectively [40]. However, in vivo experiments with cattle and sheep assigned lymphostatin/EFA-1 only a minor role in intestinal colonization. In comparison to wild type, mutation of lifA/efa-1 gene or pseudogene in EHEC 0157:H7 had no effect on the number of adhering bacteria in the intestines of infected animals. Further, a genome-wide search for EHEC adhesion molecules by transposon mutagenesis identified 59 bacterial genes that play a role in colonization of cattle intestine, lifA/efa- 1 was not among them [41]. This is in sharp contrast to experiments with calves [40] and mice [21] as both, lifA/efa-1 glucosyltransferase and protease motifs were essential for successful intestinal colonization. However, colonization studies with lifA/efa-l wild type and mutant $C$. rodentium in mice utilized strains with a 5' located stop codon and weak 3' ribosomal binding site and start codon in the insertion sequence. It is possible that expression of genes located downstream of the mutations is compromised and therefore a clear role in colonization of mouse intestine cannot be assigned for either motif.

In addition to an effect on eukaryotic cellular functions, studies have shown that lymphostatin/EFA-1 positively regulates endogenous prokaryotic protein expression for genes located on the LEE pathogenicity island [22,42]. Mutations of lifA/efa- 1 gene and pseudogene lead to an 8-fold reduction in bacterial espD expression, a protein critical for the type III secretion system. Similarly, inactivation of toxB decreased production and secretion of adhesion molecules EspA, EspB, and Translocated intimin receptor, as well as the number of bacterial microcolonies on intestinal epithelial cells. Therefore, it is conceivable that lymphostatin/EFA-1 and ToxB directly and indirectly regulate bacterial effector proteins, in particular, those involved in bacterial adhesion. However, these findings have not been verified in other Gram negative pathogens, like EPEC or RDEC strains.

Like tripartite toxin A and B from Clostridium spp, lymphostatin/EFA-1 harbors an N-terminal glucosyltransferase motif, when expressed alone, does not glycosylate small GTPases RhoA and Rab in vitro with UDP-glucose as a cofactor. However, it is possible that lymphostatin/EFA-1 targets a single or multiple different GTPases glycosylating the preserved threonine, utilizing a UDP-hexose like UDP-N-acetylglucosamine or UDP-galactose.

\section{Conclusion and Future Outlook}

Lymphostatin/EFA-1 is a large multi-functional toxin encoded by lifA/efa-1 and expressed in various Gram negative pathogenic bacteria. lifA/efa- 1 is significantly associated with the development of diarrhea and systemic complications caused by enteric pathogens, including EPEC and EHEC strains. Investigations of specific motifs implicated in the suppression of cytokine expression and regulation of bacterial adhesion molecules will clarify the role of lymphostatin/EFA-1 in the 
pathogenesis of Gram negative bacteria. Like large Clostridial cytotoxins, it is of interest to identify additional intracellular pathways affected by this toxin, in particular, those involving small GTPases. Further, there is limited knowledge about secretion and the cellular ligand of lymphostatin/EFA-1, whether this toxin is cleaved into smaller subunits, and the structure of this protein which is in part explained by its toxicity when expressed as a recombinant protein. It remains to be determined whether lymphostatin/EFA-1 is an ideal candidate protein for vaccine development to prevent devastating sequelae of enteric infections.

\section{References}

1. Farthing, M.J. Diarrhoea: A significant worldwide problem. Int. J. Antimicrob. Agents 2000, 14, 65-69.

2. Clarke, S.C.; Haigh, R.D.; Freestone, P.P.; Williams, P.H. Virulence of enteropathogenic Escherichia coli, a global pathogen. Clin. Microbiol. Rev. 2003, 16, 365-378.

3. Welinder-Olsson, C.; Kaijser, B. Enterohemorrhagic Escherichia coli (EHEC). Scand. J. Infect. Dis. 2005, 37, 405-416.

4. Noel, J.M.; Boedeker, E.C. Enterohemorrhagic Escherichia coli: a family of emerging pathogens. Dig. Dis. 1997, 15, 67-91.

5. Tobe, T.; Hayashi, T.; Han, C.G.; Schoolnik, G.K.; Ohtsubo, E.; Sasakawa, C. Complete DNA sequence and structural analysis of the enteropathogenic Escherichia coli adherence factor plasmid. Infect. Immun. 1999, 67, 5455-5462.

6. McDaniel, T.K.; Jarvis, K.G.; Donnenberg, M.S.; Kaper, J.B. A genetic locus of enterocyte effacement conserved among diverse enterobacterial pathogens. Proc. Natl. Acad. Sci. USA 1995, 92, 1664-1668.

7. Hicks, S.; Frankel, G.; Kaper, J.B.; Dougan, G.; Phillips, A.D. Role of intimin and bundleforming pili in enteropathogenic Escherichia coli adhesion to pediatric intestinal tissue in vitro. Infect. Immun. 1998, 66, 1570-1578.

8. Chong, Y.; Fitzhenry, R.; Heuschkel, R.; Torrente, F.; Frankel, G.; Phillips, A.D. Human intestinal tissue tropism in Escherichia coli O157: H7-initial colonization of terminal ileum and Peyer's patches and minimal colonic adhesion ex vivo. Microbiology 2007, 153, 794-802.

9. Mead, P.S.; Griffin, P.M. Escherichia coli O157:H7. Lancet 1998, 352, 1207-1212.

10. Klapproth, J.M.; Scaletsky, I.C.; McNamara, B.P.; Lai, L.C.; Malstrom, C.; James, S.P.; Donnenberg, M.S. A large toxin from pathogenic Escherichia coli strains that inhibits lymphocyte activation. Infect. Immun. 2000, 68, 2148-2155.

11. Ogura, Y.; Ooka, T.; Iguchi, A.; Toh, H.; Asadulghani, M.; Oshima, K.; Kodama, T.; Abe, H.; Nakayama, K.; Kurokawa, K.; Tobe, T.; Hattori, M.; Hayashi, T. Comparative genomics reveal the mechanism of the parallel evolution of O157 and non-O157 enterohemorrhagic Escherichia coli. Proc. Natl. Acad. Sci. USA 2009, 106, 17939-17944.

12. Afset, J.E.; Anderssen, E.; Bruant, G.; Harel, J.; Wieler, L.; Bergh, K. Phylogenetic backgrounds and virulence profiles of atypical enteropathogenic Escherichia coli strains from a case-control 
study using multilocus sequence typing and DNA microarray analysis. J. Clin. Microbiol. 2008, 46, 2280-2290.

13. Morabito, S.; Tozzoli, R.; Oswald, E.; Caprioli, A. A mosaic pathogenicity island made up of the locus of enterocyte effacement and a pathogenicity island of Escherichia coli O157:H7 is frequently present in attaching and effacing E. coli. Infect. Immun. 2003, 71, 3343-3348.

14. Bielaszewska, M.; Sonntag, A.K.; Schmidt, M.A.; Karch, H. Presence of virulence and fitness gene modules of enterohemorrhagic Escherichia coli in atypical enteropathogenic Escherichia coli O26. Microbes Infect. 2007, 9, 891-897.

15. Janka, A.; Bielaszewska, M.; Dobrindt, U.; Karch, H. Identification and distribution of the enterohemorrhagic Escherichia coli factor for adherence (efa1) gene in sorbitol-fermenting Escherichia coli O157: H. Int. J. Med. Microbiol. 2002, 292, 207-214.

16. Nicholls, L.; Grant, T.H.; Robins-Browne, R.M. Identification of a novel genetic locus that is required for in vitro adhesion of a clinical isolate of enterohaemorrhagic Escherichia coli to epithelial cells. Mol. Microbiol. 2000, 35, 275-288.

17. Szalo, I.M.; Goffaux, F.; Pirson, V.; Pierard, D.; Ball, H.; Mainil, J. Presence in bovine enteropathogenic (EPEC) and enterohaemorrhagic (EHEC) Escherichia coli of genes encoding for putative adhesins of human EHEC strains. Res. Microbiol. 2002, 153, 653-658.

18. Badea, L.; Doughty, S.; Nicholls, L.; Sloan, J.; Robins-Browne, R.M.; Hartland, E.L. Contribution of Efa1/LifA to the adherence of enteropathogenic Escherichia coli to epithelial cells. Microb. Pathog. 2003, 34, 205-215.

19. Tauschek, M.; Strugnell, R.A.; Robins-Browne, R.M. Characterization and evidence of mobilization of the LEE pathogenicity island of rabbit-specific strains of enteropathogenic Escherichia coli. Mol. Microbiol. 2002, 44, 1533-1550.

20. Zhu, C.; Agin, T.S.; Elliott, S.J.; Johnson, L.A.; Thate, T.E.; Kaper, J.B.; Boedeker, E.C. Complete nucleotide sequence and analysis of the locus of enterocyte Effacement from rabbit diarrheagenic Escherichia coli RDEC-1. Infect. Immun. 2001, 69, 2107-2115.

21. Klapproth, J.M.; Sasaki, M.; Sherman, M.; Babbin, B.; Donnenberg, M.S.; Fernandes, P.J.; Scaletsky, I.C.; Kalman, D.; Nusrat, A.; Williams, I.R. Citrobacter rodentium lifA/efa1 is essential for colonic colonization and crypt cell hyperplasia in vivo. Infect Immun 2005, 73, 1441-1451.

22. Tatsuno, I.; Horie, M.; Abe, H.; Miki, T.; Makino, K.; Shinagawa, H.; Taguchi, H.; Kamiya, S.; Hayashi, T.; Sasakawa, C. toxB gene on pO157 of enterohemorrhagic Escherichia coli O157:H7 is required for full epithelial cell adherence phenotype. Infect. Immun. 2001, 69, 6660-6669.

23. Perna, N.T.; Plunkett, G., 3rd; Burland, V.; Mau, B.; Glasner, J.D.; Rose, D.J.; Mayhew, G.F.; Evans, P.S.; Gregor, J.; Kirkpatrick, H.A.; Posfai, G.; Hackett, J.; Klink, S.; Boutin, A.; Shao, Y.; Miller, L.; Grotbeck, E.J.; Davis, N.W.; Lim, A.; Dimalanta, E.T.; Potamousis, K.D.; Apodaca, J.; Anantharaman, T.S.; Lin, J.; Yen, G.; Schwartz, D.C.; Welch, R.A.; Blattner, F.R. Genome sequence of enterohaemorrhagic Escherichia coli O157:H7. Nature 2001, 409, 529-533. 
24. Xie, G.; Bonner, C.A.; Jensen, R.A. Dynamic diversity of the tryptophan pathway in chlamydiae: Reductive evolution and a novel operon for tryptophan recapture. Genome Biol. 2002, 3, research0051.

25. Belland, R.J.; Scidmore, M.A.; Crane, D.D.; Hogan, D.M.; Whitmire, W.; McClarty, G.; Caldwell, H.D. Chlamydia trachomatis cytotoxicity associated with complete and partial cytotoxin genes. Proc. Natl. Acad. Sci. USA 2001, 98, 13984-13989.

26. Afset, J.E.; Bruant, G.; Brousseau, R.; Harel, J.; Anderssen, E.; Bevanger, L.; Bergh, K. Identification of virulence genes linked with diarrhea due to atypical enteropathogenic Escherichia coli by DNA microarray analysis and PCR. J. Clin. Microbiol. 2006, 44, 3703-3711.

27. Vieira, M.A.; Salvador, F.A.; Silva, R.M.; Irino, K.; Vaz, T.M.; Rockstroh, A.C.; Guth, B.E.; Gomes, T.A. Prevalence and characteristics of the $\mathrm{O} 122$ pathogenicity island in typical and atypical enteropathogenic Escherichia coli strains. J. Clin. Microbiol. 2010, 48, 1452-1455.

28. Jores, J.; Wagner, S.; Rumer, L.; Eichberg, J.; Laturnus, C.; Kirsch, P.; Schierack, P.; Tschape, H.; Wieler, L.H. Description of a 111-kb pathogenicity island (PAI) encoding various virulence features in the enterohemorrhagic E. coli (EHEC) strain RW1374 (O103:H2) and detection of a similar PAI in other EHEC strains of serotype 0103:H2. Int. J. Med. Microbiol. 2005, 294, 417-425.

29. Wickham, M.E.; Lupp, C.; Mascarenhas, M.; Vazquez, A.; Coombes, B.K.; Brown, N.F.; Coburn, B.A.; Deng, W.; Puente, J.L.; Karmali, M.A.; Finlay, B.B. Bacterial genetic determinants of non-O157 STEC outbreaks and hemolytic-uremic syndrome after infection. J. Infect. Dis. 2006, 194, 819-827.

30. Karmali, M.A.; Mascarenhas, M.; Shen, S.; Ziebell, K.; Johnson, S.; Reid-Smith, R.; IsaacRenton, J.; Clark, C.; Rahn, K.; Kaper, J.B. Association of genomic O island 122 of Escherichia coli EDL 933 with verocytotoxin-producing Escherichia coli seropathotypes that are linked to epidemic and/or serious disease. J. Clin. Microbiol. 2003, 41, 4930-4940.

31. Nadler, C.; Baruch, K.; Kobi, S.; Mills, E.; Haviv, G.; Farago, M.; Alkalay, I.; Bartfeld, S.; Meyer, T.F.; Ben-Neriah, Y.; Rosenshine, I. The type III secretion effector NleE inhibits NFkappaB activation. PLoS Pathog. 2010, 6, e1000743.

32. Aktories, K.; Barbieri, J.T. Bacterial cytotoxins: Targeting eukaryotic switches. Nat. Rev. Microbiol. 2005, 3, 397-410.

33. Shao, F.; Merritt, P.M.; Bao, Z.; Innes, R.W.; Dixon, J.E. A Yersinia effector and a Pseudomonas avirulence protein define a family of cysteine proteases functioning in bacterial pathogenesis. Cell 2002, 109, 575-588.

34. Klapproth, J.M.; Donnenberg, M.S.; Abraham, J.M.; Mobley, H.L.; James, S.P. Products of enteropathogenic Escherichia coli inhibit lymphocyte activation and lymphokine production. Infect. Immun. 1995, 63, 2248-2254.

35. Klapproth, J.M.; Donnenberg, M.S.; Abraham, J.M.; James, S.P. Products of enteropathogenic E. coli inhibit lymphokine production by gastrointestinal lymphocytes. Am. J. Physiol. 1996, 271, G841-G848. 
36. Malstrom, C.; James, S. Inhibition of murine splenic and mucosal lymphocyte function by enteric bacterial products. Infect. Immun. 1998, 66, 3120-3127.

37. Abu-Median, A.B.; van Diemen, P.M.; Dziva, F.; Vlisidou, I.; Wallis, T.S.; Stevens, M.P. Functional analysis of lymphostatin homologues in enterohaemorrhagic Escherichia coli. FEMS Microbiol. Lett. 2006, 258, 43-49.

38. Beatty, W.L.; Belanger, T.A.; Desai, A.A.; Morrison, R.P.; Byrne, G.I. Tryptophan depletion as a mechanism of gamma interferon-mediated chlamydial persistence. Infect. Immun. 1994, 62, 3705-3711.

39. Babbin, B.A.; Sasaki, M.; Gerner-Schmidt, K.W.; Nusrat, A.; Klapproth, J.M. The bacterial virulence factor lymphostatin compromises intestinal epithelial barrier function by modulating rho GTPases. Am. J. Pathol. 2009, 174, 1347-1357.

40. Stevens, M.P.; van Diemen, P.M.; Frankel, G.; Phillips, A.D.; Wallis, T.S. Efa1 influences colonization of the bovine intestine by shiga toxin-producing Escherichia coli serotypes $\mathrm{O} 5$ and O111. Infect. Immun. 2002, 70, 5158-5166.

41. Dziva, F.; van Diemen, P.M.; Stevens, M.P.; Smith, A.J.; Wallis, T.S. Identification of Escherichia coli O157:H7 genes influencing colonization of the bovine gastrointestinal tract using signature-tagged mutagenesis. Microbiology 2004, 150, 3631-3645.

42. Stevens, M.P.; Roe, A.J.; Vlisidou, I.; van Diemen, P.M.; La Ragione, R.M.; Best, A.; Woodward, M.J.; Gally, D.L.; Wallis, T.S. Mutation of toxB and a truncated version of the efa-1 gene in Escherichia coli O157:H7 influences the expression and secretion of locus of enterocyte effacement-encoded proteins but not intestinal colonization in calves or sheep. Infect. Immun. 2004, 72, 5402-5411.

(C) 2010 by the authors; licensee MDPI, Basel, Switzerland. This article is an open-access article distributed under the terms and conditions of the Creative Commons Attribution license (http://creativecommons.org/licenses/by/3.0/). 